\title{
Conservação e restauro: sector da actividade económica versus domínio científico-tecnológico - uma realidade, uma ficção ou uma utopia?
}

\author{
Fernando dos Santos Antunes
}

Resumen: En este artículo se abordan cuestiones relacionadas con la conservación y restauración, mediante el análisis de sus dos principales campos de acción. Por un lado, el ámbito del mercado de trabajo como un sector de actividad económica y, por otra parte, el ámbito de la educación/formación (sólo de nivel superior) como dominio científico-tecnológico. Al abordar estos dos aspectos, se trata de leer la realidad, identificando los aspectos positivos y negativos de los sistemas de clasificación y de marco jurídico que se aplican a las dos áreas identificadas (sector y dominio de actividad), derivados por las disposiciones legales y reglamentarias de las organizaciones internacionales y nacionales. Al mismo tiempo, se incluye una recopilación de la oferta formativa en Conservación y Restauración de las Instituciones de Educación Superior Portuguesas, que resulta de la reforma del Sistema de Educación Europeo prevista en la Declaración de Bolonia, que prevé la creación de un Espacio Europeo de Educación Superior.

Palabras clave: conservación y restauración, oferta de formación, sistema de cualificación, actividad económica, clasificación de dominios científicos y tecnológicos, educación superior.

Abstract: This article discusses issues related to Conservation and Restoration, by analyzing its two major fields. In one hand, the field of the labour market, as a sector of economic activity, and on the other hand, the field of the education/formation (concerning higher education only) as a scientific-technological field. In addressing these two aspects, we seek for their reality, identifying the positives and negatives of the classification and legal context systems, that applies to both identified areas (sector and field of activity), made by the normative and legislative production of the international and national (Portuguese) organisms. At the same time, is carried out a survey about the education offer in Conservation and Restoration of the Portuguese Higher Education, resulting from the change of the European Education System, provided by the Bologna Declaration, which foresees the creation of a European Higher Education Area.

Keywords: conservation and restoration, educational offer, professional qualification system, economic activity classification system, science and technology classification system, higher education

Resumo: Neste artigo abordam-se questões relacionadas com a Conservação e Restauro, analisando os seus dois grandes campos de acção. Por um lado, pela vertente do mercado de trabalho, como sector de actividade económica, e, por outro lado, pela vertente do ensino/formação (tratando o ensino superior), como domínio científico-tecnológico. $\mathrm{Na}$ abordagem destas duas vertentes, procura ler-se a sua realidade, identificando os aspectos positivos e negativos dos sistemas de classificação e de enquadramento legal, que se aplicam às duas vertentes identificadas (sector e domínio de actividade), decorrentes da produção normativa e legislativa dos organismos internacionais e nacionais. Paralelamente, inclui-se um levantamento da oferta formativa em Conservação e Restauro das Instituições de Ensino Superior Português que resulta da reforma do Sistema de Ensino Europeu previsto na Declaração de Bolonha e que prevê a criação de um Espaço Europeu de Ensino Superior.

Palavras-chave: conservação e restauro, oferta formativa, sistema de qualificação profissional, classificação de actividades económicas, classificação de domínios científicos e tecnológicos, ensino superior 


\section{Introdução}

Neste artigo propomo-nos reflectir sobre a dicotomia da actividade da Conservação e Restauro (CR) entre sector de actividade económica e domínio científico-tecnológico, começando por abordar um contributo dado em Portugal para delimitação desta actividade. Na primeira parte abordaremos os problemas levantados ao sector pelo sistema de Classificacãa de Actividades Económicas - Revisão 3 (CAE-Rev.3). Na segunda parte, os problemas levantados ao domínio com o sistema de Classificação de Dominios Cientificos e Tecnológicos (CDCT) - Fields of Science and Technology (FOS), apresentaremos a oferta formativa de nível superior em CR que decorre da "reforma de Bolonha" e os problemas levantados com o respectivo Sistema de Qualificação Profissionais (SQP) que resulta da aplicação das suas determinações e que fixa os Niveis de Qualificação Profissional (NQP) dos vários níveis e graus de ensino/formação.

Para tornar a leitura mais fácil, dada a limitação de palavras definida e porque o tema desenvolvido conduz a uma sistemática referência a organizações, documentos legais e sistemas de classificação, decidimos utilizar as respectivas siglas já convencionadas pelo que sugerimos ao leitor consultar, no fim deste artigo, a lista de abreviaturas e siglas ordenada alfabeticamente.

\section{Um contributo para a delimitação do sector de actividade e o seu sucesso ou insucesso.}

Completados 11 anos que os Ministros da Educação Europeus, subscreveram a Declaração de Bolonha [19/06/1999], cujos alicerces tinham sido lançados um ano antes [25/05/1998] pela Declaração da Sorbonne, que criou as bases da constituição de uma "Europa do Saber". Estando, também, a decorrer o ano (de 2010), fixado como data limite para o estabelecimento do Espaço Europeu de Ensino Superior (EEES) - European Higher Education Area (EHEA)1, o grande desígnio de "Bolonha", e que fixou como principal objectivo deste espaço ou sistema de ensino superior, caracterizadamente, "multinacional", "multiformativo e educativo", e "multicultural" (características que aparenta manter, acrescentamos nós), o estabelecimento dos "princípios" da coerência, da compatibilidade da competitividade, e da atractividade para estudantes do espaço europeu e de outros espaços ou países (curiosamente, princípios fundamentais para o sector da actividade profissional e para o domínio cientifico e tecnológico da conservação e restauro). E quando se aproximam os cinco anos do momento que foi dado início pelo Governo da República Portuguesa (GRP) do processo político e legislativo de reforma do Sistema de Ensino Superior Português (SESP) e das Instituições de Ensino Superior Português (IESP), para permitir a aplicação da reforma prevista no "espírito" e clausulado da Declaração de Bolonha $a^{2}$, com a publicação de um pacote legislativo que tem a encimá-lo a alteração da Lei de Bases do Sistema Educativo (Lei N. ${ }^{\circ}$ 49/2005, de 30 de Agosto) e subsequentes diplomas legais de regulamentação às alterações desta lei, assumidos como estruturantes do SESP, dos quais se destaca o Decreto-Lei $n^{\circ}$ 74/2006, de 24 de Março, sobre Graus Académicos e Diplomas do Ensino Superior, preconizando já o novo modelo de organização do SESP no que respeita aos ciclos de estudos. Tendo sido fixado pelo GRP às IESP Politécnico e Universitário - um período de dois anos (entre os anos lectivos de 2006/2007 e 2007/2008) para adequação das suas formações a este novo enquadramento normativo que estabelece como principal paradigma a transição de "um modelo de ensino passivo, baseado na aquisição de conhecimentos, para um modelo baseado no desenvolvimento de competências, onde se incluem, quer as de natureza genérica - instrumentais, interpessoais e sistémicas - quer as de natureza específica, associadas à área de formação, $e$ onde a componente experimental e de projecto desempenhariam um papel importante." (cit.) ${ }^{3}$.

Pareceu-nos interessante, aproveitando o convite do Grupo Espanhol do International Institute for Conservation of Historic and Artistic Works (GE-IIC), voltar a este tema, sem a pretensão de fazer um qualquer balanço, até porque não seria possível fazê-lo no "tempo" deste artigo e o tema é demasiado importante para todos, para que seja tratado sem um estudo (obrigatório - que já se impõe) mais minucioso e demorado desta realidade, assente em metodologia científica 
consubstanciada e validada a partir de um levantamento (com base em inquéritos aos vários autores do sistema) e respectivo enquadramento estatístico, que seriam fundamentais para um conhecimento efectivo deste sector/domínio de actividade.

O pretexto da escolha deste tema também se reforça na medida em que corresponde ao tema de um estudo publicado em Abril de 2006, mandado realizar pelo GRP, através do Ministério do Trabalho e da Solidariedade Social (MTSS), e do Instituto para a Qualidade na Formação (IQF), no âmbito do Programa Operacional de Assistência Técnica ao Quadro Comunitário de Apoio III - Eixo Fundo Social Europeu. Tratou-se de um projecto que consistiu na elaboração de um estudo prospectivo sobre a necessidade de qualificações para o sector da actividade económica da "Preservação, Conservação e Valorização do Património Cultural em Portugal" (PCVPC), por um consórcio (constituído pela empresa PERFIL - Psicologia e Trabalho, Lda., de Lisboa, e o Instituto Politécnico de Tomar Portugal, e que integrou vários especialistas em estudos sectoriais das áreas do trabalho, do património cultural e da conservação e restauro) cujo trabalho de campo e desenvolvimento da metodologia operacional (de levantamento da oferta formativa, de realização de estudos-de-caso, análise de resultados, tratamento de informação e redacção) decorreu, aproximadamente, entre o último trimestre de 2003 e meados de 2005.

Este estudo inseriu-se em um conjunto mais vasto de estudos de natureza profissional e sectorial (cobrindo desde os sectores primário, secundário e terciário, ou dos serviços, onde se incluem as actividades do sector da PCVPC, nos seus campos de actuação publico e privado, institucional e particular). Teve como objectivos gerais: a elaboração um retrato fiel da evolução das qualificações e o diagnóstico das necessidades de formação. Como objectivos específicos: propôs-se a realizar delimitação e caracterização do sector de actividade económica e a conhecer a evolução dos empregos, das qualificações e competências; e do domínio educativo e da formação profissional, de acordo com as necessidades formativas, de modo a propor pistas para a reorientação da formação bem como estratégias de resposta às necessidades de competências do mercado profissional.

Paralelamente, a equipa que desenvolveu o estudo delineou os perfis profissionais específicos a este sector profissional e perfis comuns a outros sectores de actividade, tendo excluído por opção/imposição metodológica os perfis transversais a vários sectores de actividade (e. g. o perfil do Historiador), fechando o estudo com a proposta de três cenários para o sector/domínio da actividade (do mais positivo para o mais negativo): dinamismo global; aprofundamento dual; estagnação e fragmentação. No que toca aos perfis profissionais a metodologia passou por estabelecer, para cada um: os referenciais de emprego, referenciais de competências mobilizáveis; formação e experiência exigidos; especificidades do mercado de trabalho e, por fim, elementos de prospectiva. (IQF - Estudo Sectorial 31, 2006: 53-57).

Quando se deu início ao estudo, cedo se percebeu que o sector/domínio da actividade da Conservação e Restauro (CR) em Portugal não constituía então, ainda, um sector estruturado da economia, em que as actividades e profissões centrais se encontrassem claramente definidas e classificadas em função de objectivos de produção de bens ou serviços. Contudo, face a uma evidente centralidade da salvaguarda, preservação e conservação do património, em geral, a par com a afirmação de identidades profissionais associadas ao trabalho no sector do património cultural (sobretudo no último quartel do século XX), permitiram antever o esboço de um sector autonomizado, em função de objectivos de produção de bens ou serviços (IQF, Estudo Sectorial 31, 2006: 11-12).

Passados que estão quatro anos daquela publicação, e face à actual conjuntura de crise económicofinanceira com o consequente reflexo nas estruturas organizacionais do sector - institucionais, empresariais e laborais - impõe avaliar-se se o sector conquistou, ou não, definitivamente e de modo inquestionável para os agentes envolvidos, essa autonomia e respectiva afirmação de identidades profissionais? E em que medida a legislação sobre o património, contribui, ou não, para 
esse percurso de valorização profissional que se espera assente em matriz conceptual, filosófica e política, adequada ao novo contexto sociocultural, educativo/formativo e, sobretudo, que se paute por modernidade e equilíbrio na distribuição dos conteúdos funcionais para os vários autores Profissionais, quer na perspectiva restrita, de preservação da nossa memória histórica, e portanto da nossa identidade cultural, quer em sentido mais amplo, quando associada à defesa e conservação da natureza e do equilíbrio ecológico e ambiental e, portanto, inserida na problemática dos modos de desenvolvimento sustentável.

\subsection{O Sector da Conservação e Restauro e o Sistema de Classificação de Actividades Económicas - Revisão 3 (CAE-Rev.3)}

$\mathrm{Na}$ época em que foi desenvolvido o estudo sobre PCVPC, e dadas as dificuldades que a equipa do consórcio, constituído para o efeito, sentiu em encontrar dados estatísticos, disponibilizados de modo claro e conclusivo pelas entidades nacionais, comunitárias e, até, internacionais, relacionadas com o levantamento e análise estatística da sociedade e economia, como é, no caso português, o Instituto Nacional de Estatística (INE), já que o sector em estudo encontrava-se (e, ao que parece, ainda se encontra) disperso por múltiplas áreas de actividade, muitas das quais não faziam parte do objecto de estudo; e dado que era imprescindível reunir dados que contivessem elementos informativos de modo a permitir caracterizar este sector de actividade, recorreu-se, para o efeito, ao quadro central de organização da informação estatística nacional, à CAE (IQF - Estudo Sectorial 31, 2006: 19).

Após a delimitação do sector de actividade, considerou esta equipa, poder circunscrever-se como objecto de estudo o enquadramento das actividades e funções específicas relacionadas com a gestão, a salvaguarda, a preservação, a conservação e restauro, e a valorização do património (histórico, artístico e cultural), em geral, e, em particular, dos bens culturais que o configuram, ou seja, lhe dão materialidade, e as profissões nele intervenientes.

Finalmente, e após a realização, conclusão e publicação do estudo sobre o património cultural (Abril, 2006) sobre o qual nos temos vindo a debruçar neste ponto, surge a revisão mais recente com a CAE-Rev.3, constante do Decreto-lei no 381/2007, de 14 de Novembro (INE, 2007: 37 38) ${ }^{4}$. De acordo com Artigo 8, ponto 2, do o Regulamento (CE) no 1893/2006, do Parlamento e Conselho Europeus, de 20 de Dezembro de 2006, "as estatísticas relativas às actividades económicas, realizadas a partir de 1 de Janeiro de 2008 serão produzidas, pelos Estados-membros, usando a Nomenclatura Geral das Actividades Económicas das Comunidades Europeias (NACE-Rev.2) ou uma nomenclatura nacional dela derivada". Para dar cumprimento ao plano de implementação da NACE-Rev.2 em todos os estados membros, o Ficheiro de Unidades Estatísticas do INE foi reclassificado em CAE-Rev.3 no decorrer do ano de 2007, de modo a ser disponibilizado aos utilizadores a partir de Janeiro de 2008 em: [http://webinq.ine.pt/public/files/consultacae.aspx].

De acordo com este normativo em vigor é evidente que os próximos Recenseamentos da População e Habitação (Censos), já programados (e que tem ocorrido nas últimas décadas, em Portugal, em intervalos de 10 anos), com as operações estatísticas a arrancarem no próximo ano de 2011, já irão fazer uso deste quadro normativo legal. Contudo, quando procuramos fazer uma pesquisa tão simples, e óbvia (para todos os profissionais da CR), como é procurar a designação da sua actividade ("conservação e restauro"), eis que se esbarra, ora em aparentes e incompreensíveis lapsos (?), ora em incongruências normativas ou classificativas (?).

Constata-se que a última década de organização (mesmo considerando as suas debilidades, mas sobretudo, não esquecendo as suas virtudes, ou seja, o que de positivo alcançou em termos de afirmação social, empresarial, profissional, económica e cultural) e de estruturação deste sector de actividade económica - PCVPC - chamemos-lhe do "património cultural", para simplificar (e onde poderia ser considerado um, de entre vários subsectores, o sector da CR), e dos respectivos 
profissionais, não está minimamente espelhado neste sistema de classificação - CAE - pois, parece ostensiva e incompreensivelmente arcaico e distante da realidade económica, socioprofissional e empresarial que pode, muito facilmente, observar-se andando no terreno.

Objectivamente, se tentarmos listar o descritivo das actividades ligadas ao sector da CR no Índice das Actividades da CAE-Rev.3 [<http://metaweb.ine.pt/sine/UInterfaces/SineInd_Ent.aspx $>$ ], antes de mais, verifica-se que, na sua ordenação alfabética, se tentarmos listar por "conservação" ou "preservação", não encontramos nenhuma entrada com indicação de categoria CAE; só mesmo listando por "restauro" (termo que até seria bom ir-se, progressivamente abandonando), e aí aparecem-nos, paradoxalmente, as seguintes entradas com a indicação das respectivas categorias CAE [tabela 1]

Tabela 1. A actividade de [Conservação e] Restauro e as várias categorias funcionais.

\begin{tabular}{|l|c|}
\hline Designação da Actividade [a] & $\begin{array}{c}\text { Categoria } \\
\text { | CAE-Rev.3 | }\end{array}$ \\
\hline RESTAURO: & $\mathbf{9 0 0 3 0}$ \\
\hline - DE ALTARES, ARTE SACRA, ETC & 41200 \\
- DE EDIFÍCIOS & $\mathbf{7 4 2 0 0}$ \\
- DE FOTOGRAFIAS ANTIGAS & $\mathbf{9 0 0 3 0}$ \\
\hline
\end{tabular}

[a] Fonte: INE (Instituto Nacional de Estatística -Portugal)<

http://metaweb.ine.pt/sine/UInterfaces/SineInd_ent.aspx?innerSysrid=0007085760> [Consultado: 21/07/2010]

Seguindo a consulta, e à medida que se escrutinam as várias categorias relacionadas, verifica-se que os respectivos descritores não espelham a realidade funcional deste sector de actividade económica, e, muito menos, servem os (bons) interesses dos seus agentes: empresários, trabalhadores e até dos clientes (que, certamente, gostariam de ter empresas certificáveis e certificadas a oferecer e prestar bons serviços, em ambiente de sã concorrência, com garantias de qualidade, transparência, e responsabilidade civil, incluída) - pois, tal como esta classificação se apresenta, e impõe pela sua regulamentação (que tem implicações em termos estatísticos e em termos fiscais), presta-se a equívocos e, quem sabe, não potenciará injustiças no acesso aos procedimentos concursais para obras publicas (de intervenções no património do Estado) que estão, naturalmente, vinculados a legislação nacional.

A título ilustrativo do que atrás foi dito, a seguir na [figura 1], propomos a observação da Ficha CAE-Rev.3, do INE, da primeira categoria elencada na [tabela 1]. "Restauro de altares, arte sacra, etc.", por ser aquela que mais especialidades e sub-especialidades abrange.

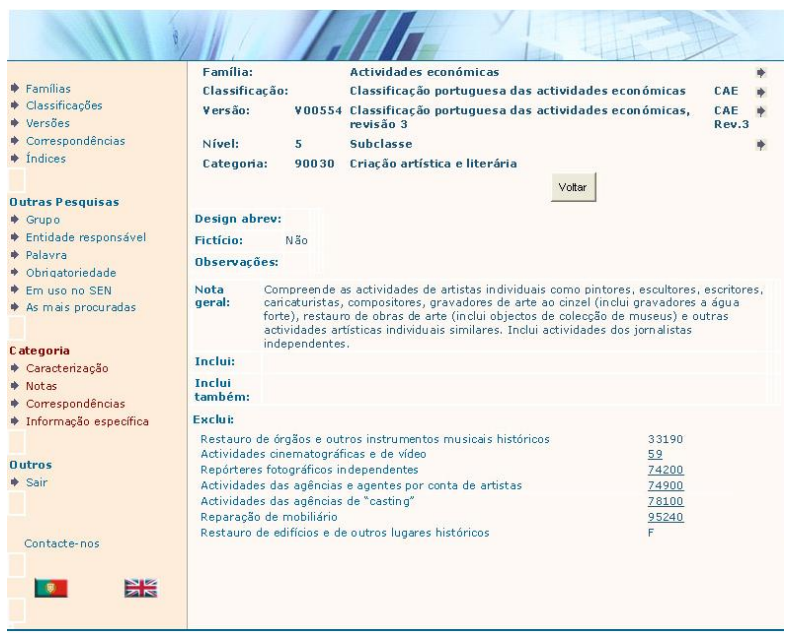

Figura 1. Ficha da Classificação Portuguesa de Actividades Económicas - CAE-Rev.3 [a]

[a] Disponível em: http://metaweb.ine.pt/SINE/UInterfaces/SineCat.as px [consultado: $23 / 7 / 2010]$ 
Tabela 2. Repertório de Actividades Artesanais em Portugal [a]

\begin{tabular}{|c|c|c|}
\hline \multicolumn{3}{|c|}{ Restauro de Património, Móvel e Integrado } \\
\hline Número & Nome & CAE \\
\hline$\underline{10.01}$ & Restauro de Património, Móvel e Integrado - Têxteis & 95290 \\
\hline$\underline{10.02}$ & Restauro de Património, Móvel e Integrado - Cerâmica & 95290 \\
\hline$\underline{10.03}$ & Restauro de Património, Móvel e Integrado - Peles e Couros & 95230 \\
\hline 10.04 & Restauro de Património, Móvel e Integrado - Madeira & 95240 \\
\hline$\underline{10.05}$ & Restauro de Património, Móvel e Integrado - Metais & 95290 \\
\hline 10.06 & Restauro de Património, Móvel e Integrado - Pedra & 95290 \\
\hline$\underline{10.07}$ & Restauro de Património, Móvel e Integrado - Papel & 95290 \\
\hline$\underline{10.08}$ & Restauro de Património, Móvel e Integrado - Instrumentos Musicais & 95290 \\
\hline 10.09 & Restauro de Património, Móvel e Integrado - Pintura & 90030 \\
\hline
\end{tabular}

Restauro de Bens Comuns

\begin{tabular}{|l|l|l||}
\hline$\underline{11.01}$ & Restauro de Bens Comuns - Têxteis & 95290 \\
\hline \hline$\underline{11.02}$ & Restauro de Bens Comuns - Cerâmica & 95290 \\
\hline \hline$\underline{11.03}$ & Restauro de Bens Comuns - Peles e Couros & 95230 \\
\hline \hline$\underline{11.04}$ & Restauro de Bens Comuns - Madeira & 95240 \\
\hline \hline$\underline{11.05}$ & Restauro de Bens Comuns - Metais & 95290 \\
\hline$\underline{11.06}$ & Restauro de Bens Comuns - Pedra & 95290 \\
\hline \hline$\underline{11.07}$ & Restauro de Bens Comuns - Papel & 95290 \\
\hline \hline$\underline{11.08}$ & Restauro de Bens Comuns - Instrumentos Musicais & 952 \\
\hline \hline$\underline{11.09}$ & Restauro de Bens Comuns - Pintura & 90030 \\
\hline
\end{tabular}

[a] Página oficial do Programa de Promoção dos Ofícios e das Microempresas Artesanais (PPART) - é uma iniciativa governamental aprovada pela Resolução do Conselho de Ministros n. ${ }^{\circ}$ 136/97, de 14 de Agosto, e o desenvolvimento deste Programa compete ao IEFP, I.P., de acordo com a Resolução do Conselho de Ministros n. ${ }^{\circ}$ 39/2006, de 21 de Abril. Disponível em: http://www.ppart.gov.pt/principal.aspx?pagina $=$ reportorio\&tipo=1 [consultado em 25/07/2010]

Por outro lado, se tentarmos listar uma qualquer empresa ligada com o sector da CR, não se encontra nenhuma referência relacionada. Encontra-se, a custo, listando com a designação social de alguma das empresas que conhecemos deste mercado, no entanto, o espanto virá quando observarmos as designações/classificações que lhes são conferidas (onde é patente esse desfasamento com a realidade), que estão direccionadas para o "fabrico de", "produção de", "construção de", "comércio de", "reparação de", "manutenção de", "actividades artísticas", "revestimentos", "engenharia", "outras actividades de" "associações de", etc.

Verificam-se, realmente, inclusões, omissões e exclusões de sectores e subsectores, sem grande nexo organizacional e funcional. Constata-se, ainda, que colocam a CR (e sem qualquer 
menosprezo pelas actividades a seguir mencionadas, que, naturalmente, também tem o seu perfil, ou cunho próprio, sendo que, algumas delas até têm, ou podem ter, estreita ligação ao sector de actividade da CR, sem que umas e outras percam a sua identidade) num "universo" ligado, aleatoriamente, à produção ou às artes, à tecnologia ou à ciência, já para não falar das conexões inusitadas com o "mundo do desporto", do "jornalismo independente", e com o "mundo do artesanato" que se apropria "em força", na sua regulamentação, das actividades da CR, conforme se pode observar a seguir [tabela 2].

Contudo, ao invés dos vários níveis de formação técnico-profissional, intermédia e até superior existente em Portugal, a criada "actividade artesanal dedicada à CR"(?), necessita de ter, entre outros requisitos, fixados na Portaria $\mathrm{n}^{\circ} 1193 / 2003$, de 13 de Outubro de 2003) $)^{5}$, frequência de formação profissional ("de ação de qualificaşão com duração igual ou superior a mil e duzentas horas"), com aproveitamento, assegurada por entidade formadora acreditada; obtendo desse modo uma "carta de artesão", cuja regulamentação é estabelecida na portaria atrás mencionada, e que tem por objecto: "regular a comprovasão do domínio dos saberes e técnicas inerentes ao exercício da actividade artesanal; definir o repertório das actividades artesanais; regular o processo de reconbecimento dos artesãos e das unidades produtivas artesanais; e a organização e funcionamento do Registo Nacional do Artesanato"6. Curiosamente, e de acordo com a mesma portaria, no seu artigo $7 .^{\circ}$, ponto 5 , da Secção III, relativa à "Apreciação e decisão dos pedidos de reconbecimento", "os processos relativos a artesãos ou unidades produtivas artesanais da área do restauro de património cultural, móvel e integrado, são obrigatoriamente remetidos pelo presidente da Comissão [Comissão Nacional para a Promoção dos Ofícios e das Microempresas Artesanais] ao Instituto Português da Conservaşão e Restauro (IPCR) [actualmente: Instituto dos Museus e da Conservação (IMC)] para, no prazo de 20 dias, emitir parecer vinculativo, nos termos do disposto no $n^{\circ} 3$ do artigo $16 .^{\circ}$ do Decreto-Lei $n .{ }^{\circ}$ 41/2001, de 9 de Fevereiro, com a redaçãa que lhe foi dada pelo Decreto-Lei n. ${ }^{\circ} 110 / 2002$, de 16 de Abril." (cit.), já que a Comissão tem que designar um grupo de trabalho que tenha pelo menos dois membros do sector. Portanto, é uma situação que, pelo menos legalmente, vincula o organismo máximo de tutela dos museus, e os responsáveis envolvidos funcionalmente no processo, de acordo com os pareceres que elaborarem para a referida Comissão responsável pela emissão das cartas de artesão.

Para terminar este ponto não poderíamos deixar de destacar dois aspectos que em nosso entender demonstram a necessidade de articulação e integração da produção legislativa entre os vários serviços do Estado Português, mas também das produções legislativas comunitária e internacional, que, ao serem transpostas para a o direito nacional, podem gerar dificuldades de funcionamento dos organismos e dos cidadãos, ao estabelecerem linhas de orientação e de regularão divergentes ou, mesmo situações de conflito.

O primeiro, pela negativa, a omissão, ou incongruente articulação, que a CAE-Rev.3 faz da ligação umbilical entre os subsectores da CR, e dos arquivos e bibliotecas e dos museus, naquilo que pode ser considerado o "sector do património cultural". Portanto, verifica-se que a CAE não considera da melhor forma um sistema de desdobramento de tipologias funcionais de empresas por áreas, especialidades, e sub-especialidades, e que nem sequer dão a importância ou a melhor interpretação ao estudo sectorial encomendado e publicado pelo Estado Português que, aparentemente, ainda não colheu os melhores frutos.

O segundo, pela positiva, embora ajude ainda a comprovar as debilidades e contradições legislativas, corresponde a um notável avanço neste campo pelo facto de ser exigida, a um técnico de CR, para poder apresentar relatório prévio a obras ou intervenções de CR em bens culturais móveis, formação académica com duração de 5 anos, somados aos quais, mais cinco anos de experiência profissional, após a obtenção do grau académico (e, consequentemente, o título profissional de Conservador-Restaurador). Trata-se de um aspecto determinante que pode ser observado nos pontos 1 e 2 do Artigo 18, do Decreto-Lei n. ${ }^{\circ}$ 140/2009, de 15 de Junho, apesar de o legislador ter deixado uma excepção neste mesmo artigo, no seu ponto três, que serve apenas para 
os bacharéis em CR, do regime "pré-Bolonha", ou para os licenciados em CR, do regime "pósBolonha", desde que fundamentada e desde que uns e outros tenham os cinco anos de experiência profissional na área da especialidade 7 . Portanto, neste caso, os interesses do património cultural e daqueles que nele intervêm para o conservar e restaurar, foram bem acautelados.

\section{O Domínio da Conservação e Restauro e o Sistema de Classificação de Domínios Científicos e Tecnológicos (CDCT) - Fields of Science and Technology (FOS)}

Neste ponto, na mesma linha de abordagem anterior, relativamente ao sector de actividade económica da CR e o respectivo sistema de classificação de actividades, pareceu-nos, também, importante analisar o modo como o "Dominio da CR" surge referenciado no sistema de CDCT - na sua revisão de 2007.

Em primeiro lugar, porque estamos a atingir as três décadas do lançamento dos alicerces, ou se quisermos os primórdios, da formação de nível superior em CR em Portugal, com as acções de ensino-formação especializadas, reconhecidas como equiparadas a um nível superior, promovidas, pela então Secretaria de Estado da Cultura, no Instituto José de Figueiredo, em Lisboa, e no Museu Monográfico de Conímbriga, em Condeixa; e há cerca de um quarto de século que essa formação se inicia em IESP, nomeadamente: na Escola Superior de Tecnologia de Tomar, que ainda existe como unidade orgânica do Instituto Politécnico de Tomar, e onde, desde 1987, se têm leccionado cursos em conservação e restauro de $10^{\circ}$ e $2 .^{\circ}$ ciclo, conferindo os graus académicos de bacharel (extinto com a reforma do sistema decorrente do "Processo de Bolonha"), licenciado e, actualmente, de mestre; na Escola Superior de Conservação e Restauro de Lisboa, criada, no final dos anos oitenta, na sequência das acções do início dessa década, sob na tutela da Secretaria de Estado da Cultura e associada à estrutura do Instituto José de Figueiredo. Mais tarde em 1999 viria a ser encerrada e integrada na Universidade Nova de Lisboa e onde hoje são leccionados cursos de CR nos três ciclos de formação superior: Entretanto, foi em 1996 que surgiu a Escola das Artes, da Universidade Católica do Porto, que começou por leccionar o $2 .^{\circ}$ ciclo de então, com curso de Licenciatura em Arte Sacra que integrava vertente de conservação e que, actualmente, assegura os três ciclos de estudos em CR. Estas três instituições, têm-se mantido na linha da frente do ensino/formação neste domínio, mas desde então para cá, e sobretudo com a adequação do sistema de ensino ao "modelo de Bolonha", que tem surgido várias IESP a concorrerem com a sua oferta formativa no mesmo domínio (IQF, Estudo Sectorial 31, 2006: 158-159).

Em segundo lugar, porque consideramos que, passadas as três décadas referidas, a $\mathrm{CR}$, como domínio científico e tecnológico, é tempo de ser reconhecida como ciência dotada de identidade própria e não uma actividade artesanal - não é compaginável com a realidade existente e com a que se prospectiva nacional e internacionalmente. Podemos mesmo, com forte convicção, arriscar o prognóstico de que, na próxima década, a CR atingirá a maturidade científica (ainda que seja, comparativamente, uma jovem ciência), considerando que, com a abertura do $3 .^{\circ}$ ciclo e respectivos programas doutorais, quer no ensino público, quer privado, é de antecipar a chegada de um nova geração de especialistas doutorados em CR. Especialistas esses, que começaram por fazer a sua formação inicial em CR, e, paralelamente, os seus percursos profissionais, no correspondente sector de actividade económica, conjugando experiência profissional com todo um percurso de ensino superior (do $1 .^{\circ}$ ao $3 .^{\circ}$ ciclo) tendente à especialização neste domínio científico, o que, naturalmente, constitui uma mais-valia para o contexto do património cultural português e mesmo europeu, pelo nível de maturidade científica e profissional que é de prever atingirem.

Citando o químico (da conservação) João Antunes (IPCR, Actas 2. ${ }^{\circ}$ Encontros Científicos, 2003: 76) “(...) a ciência da conservação é [pode vir a ser] uma disciplina autónoma, basta-se por si e tem valor suficiente para não necessitar da adição de disciplinas clássicas para obter credibilidade. Existe uma certa tendência para se pensar que a Conservação tem de estar associada à História, on à Matemática, on à Quimica que é o 
conhecimento clássico, para ter validade e ser credivel. Isso não é assim, a Conservação vale como tal, a Conservação utiliza a ciência clássica para atingir os seus objectivos".

Claro que é uma disciplina que, "apesar de se bastar a si própria", necessita da concorrência partilhada e integrada de outros domínios científicos, aos quais J. Antunes designou de clássicos, sem que se verifiquem sobreposições ou anulações de uns em relação a outros em função dos seus pesos (sempre) relativos.

Neste campo a verdadeira questão é que todos os agentes intervenientes, desde a regulação do ensino, às IES, aos alunos, de modo integrado e partilhado, devem, depois de reconhecerem os perfis profissionais desejados/desejáveis para o sector, identificar verdadeiramente as necessidades formativas para, consequentemente, ajustarem as estruturas dos cursos e respectivos conteúdos, sem perda da sua identidade, autonomia e independência cientifica, às verdadeiras necessidades dos profissionais e do mercado, e só assim, em nosso entender, estaremos em condições de caminhar para plena certificação e acreditação dos intervenientes - estabelecimentos de ensino/formação, profissionais e empresas do sector.

Mas, por outro lado, também é importante que os instrumentos de análise estatística, empregues para avaliar a realidade, tomem em linha de conta este segmento do ensino, o reconheçam, em si e à sua identidade, para que as conclusões possam ser representativas da realidade e não apareçam sempre maquilhadas por resultados de outros domínios afins ou relacionados, para onde, sistematicamente, a CR é remetida aleatoriamente. Neste caso, o instrumento utilizado para fins de aproveitamento estatístico, de acordo com o Gabinete de Planeamento, Estratégia, Avaliação e Relações Internacionais (GPEARI) do Ministério da Ciência, Tecnologia e Ensino Superior (MCTES), é a CDCT - 2007, cuja actualização foi aprovada em Diário da República, D.R. no 65/2008, de 2 de Abril, II Série, na sequência da revisão da classificação FOS no Manual de Frascati de 2006, pelo National Experts on Science and Technology Indicators (NESTI) - Grupo de Peritos Nacionais em Indicadores de Ciência e Tecnologia ${ }^{8}$.

A actualização da CDCT - 2007 (FOS) permitiu adequar a classificação dos domínios científicos e tecnológicos em uso no SEN, à classificação vigente em termos comunitários e internacionais (utilizada pela OCDE - Organização para a Cooperação e Desenvolvimento Económico e EUROSTAT European Statistics). O domínio científico é utilizado ainda para efeitos de caracterização dos recursos humanos altamente qualificados no âmbito do Inquérito aos Doutorados (CDH) e dos Doutoramentos realizados e reconhecidos em universidades portuguesas ${ }^{9}$.

Da análise da oferta formativa em CR, em Portugal, verifica-se que, nos seus programas de estudos, de uma maneira geral e de forma mais ou menos equitativa, têm representadas, nas respectivas unidades curriculares, as áreas relacionadas com as ciências exactas, da terra e da natureza; as ciências sociais; as ciências humanas; e, naturalmente, a área cientifica (e tecnológica) da CR, que, desde a sua fundação académica, como domínio cientifico, se mantém órfã de qualquer sistema de classificação (nacional ou internacional, nos quais o nacional é inspirado). A área científica da CR não consta descrita na lista de CDCT - 2007 (FOS), em nenhuma das suas seis Grandes Áreas, nem sequer na Grande Área das Humanidades, e, portanto, face à sua omissão neste descritivo o que se tem verificado é que os responsáveis dos mais diversos organismos nacionais - de estatística (INE), governamentais (MCTES: Direcção-Geral do Ensino Superior (DGES) e GPEARI), das IESP (Universidades e Politécnicos) - e os responsáveis pela coordenação dos ciclos de estudos, quando solicitados a atribuir classificação FOS a este tipo de cursos limitam-se modo "forçosamente alternativo", mais ou menos reflectido, mais ou menos aleatório, a indexar os cursos de CR a um domínio relacionado com qualquer uma das Grande Áreas, Subgrandes Áreas e Áreas que aparecem listadas e definidas neste sistema de classificação nacional, como são os casos da História e Arqueologia; das Artes; ou Outras Humanidades (sendo que esta área nem sequer tem qualquer nota explicativa que inclua ou exclua qualquer das "outras" áreas das humanidades, mas que, 
segundo a Classificação Internacional Tipo da Educação de 1997 (CITE), da UNESCO, inclui: interpretação e tradução, linguística, literatura comparada, história, arqueologia, filosofia, ética).

Face ao exposto, não seria útil a todos os agentes intervenientes, ponderar a indexação ao sistema de classificação FOS, na sua Grande Área das Humanidades, ou, em alternativa, a criação de uma Grande Área das Ciências e Tecnologias (?) e a criação de uma nova Subgrande Área a designar de Ciências e Tecnologias do Património Cultural (?) e a respectiva Área de Conservação e Restauro (?) podendo, ainda, eventualmente, juntarem-se-lhe as Áreas de: Ciência da Conservação (?); Gestão do Património Cultural (?); Documentalistica: Arquivística e Biblioteconomia (?); Museologia (?). Enfim, ficam estas sugestões para quem de direito e entendido no assunto as julgue e, quem sabe, um dia, as vejamos a ocupar um lugar nas listas de CDCT, que, em nosso entender, bem o merecem, na medida em que, na maioria dos casos, a oferta formativa inicial de nível superior (quer em Portugal, quer em outros países do mundo) já as contempla.

Foi-nos ainda possível coligir outro sistema de classificação, publicado pelo Ministério das Actividades Económicas e do Trabalho, na sua Portaria n. ${ }^{\circ}$ 256/2005, de 16 de Março, que regula a aplicação da Classificação Nacional de Áreas de Educação e Formação (CNAEF) e que revê a CNAEF publicada na Portaria n. $.^{\circ} 316 / 2001$, de 2 de Abril, introduzindo as alterações previstas pela CITE199710, aprovada pela Conferência Geral da UNESCO - Organização das Nações Unidas para a Educação, a Ciência e a Cultura, na sua 29. ${ }^{a}$ sessão, em Novembro de 1997, para constituir um "instrumento de classificação que permita compilar e avaliar as estatísticas educativas, tanto a nivel nacional como a nivel internacional". Incide, principalmente sobre duas variáveis de classificação cruzada: níveis de educação e áreas de estudo (UNESCO, 2006: iii).

Um aspecto que nos merece destaque é o facto de os responsáveis pela reedição desta versão portuguesa da CITE, no seu prefácio, reconhecerem a necessidade de proceder à sua revisão e actualização de "modo a facilitar a recolba e comparação das estatísticas da educação a nivel internacional, tendo em conta as mudanças e a evolução da educação e ainda antecipando futuras tendências nas várias regiões do mundo, tais como: a multiplicação e o desenvolvimento das diferentes formas de educação e de formação profissional; a diversidade crescente dos prestadores de educação; a crescente utilização do ensino a distância e outras modalidades baseadas nas novas tecnologias." (UNESCO, 2006: iii).

Merece, também, destaque e reflexão o facto de o texto da CITE reconhecer, no capítulo relativo ao seu âmbito e aplicação, que "não pretende dar uma definição completa, muito menos impor uma concep̧̧ão harmonizada a nivel internacional da filosofia, dos objectivos ou do conteúdo da educação, ou reflectir os seus aspectos culturais". (UNESCO, 2006: 9) Reconhece que pode ser improdutiva uma qualquer imposição normativa ou conceptual comum a todas as realidades nacionais, uma vez que os respectivos contextos culturais, sociais e económicos, produzirão, pelo menos, uma concepção de educação característica (então impõem-se as perguntas: porque razão a grande maioria dos estados seguem o mesmo "guião" (?); e será que todos o transpõem directamente sem adaptação às respectivas realidades nacionais (?)). O que implicará, por parte dos responsáveis nacionais, o conhecimento profundo do seu universo educativo/formativo e depois, se for do seu interesse, verificar o modo como ele pode ser ajustado à realidade preconizada pelos sistemas multinacionais (reconhecendo-os como viáveis e potenciadores de avanço), ou, ao invés, procurem produzir doutrina e agenciamento junto das autoridades internacionais, de modo a ajustarem os seus sistemas a essa doutrina - assim essas autoridades lhe reconheçam o mérito potencial. É de referir ainda que a UNESCO poderá inserir novas áreas sempre que seja necessário.

A CITE, após modificações, tem actualmente 25 áreas de estudo e 21 na versão original. Uma outra inovação consiste no estabelecimento de grandes grupos compostos por áreas de estudo que apresentam semelhanças. No nosso caso interessa referir em particular os códigos que descrevem com precisão como se afectam os programas de educação/grupos de matérias às diferentes áreas de estudo. Relativamente ao grande grupo das Artes e Humanidades (código 2), que se subdivide em 
duas áreas de estudo, por um lado, a das Artes (código 21) e, por outro, a das Humanidades (código 22), mais uma vez não encontramos nenhuma referência à CR,

De volta à aplicação da CNAEF, e à classificação que estabelece para os cursos das IESP (Politécnicos e Universidades), consideramos tratar-se de uma realidade bizarra, ficcionada e incompreensível para um qualquer profissional da $\mathrm{CR}$, ou até mesmo para um qualquer formando do $1 .^{\circ}$ ciclo de estudos, no fim do seu $1 .^{\circ}$ ano, dada a sua estranha originalidade, não verificável na prática, senão veja-se como é possível encontrar os $1 .^{\circ} \mathrm{s}, 2 .^{\circ} \mathrm{s}$ e $3 .^{\circ} \mathrm{s}$ ciclos de estudos em conservação e restauro nas várias IESP (com excepção dos Programas de Estudos do $2 .^{\circ}$ ciclo em "Ciências da Conservação", da Universidade Nova de Lisboa, e em "Química aplicada ao Património Cultural", da Universidade de Lisboa/Instituto Politécnico de Tomar, que têm atribuída a classificação de "Técnicas dos Processos Químicos") classificados, sem qualquer justificação plausível a não ser a existência de um autentico "espartilho" legal, que não reconhece e não inova, mas impõe classificações de: "Artesanato" (código 215); de "História e Arqueologia" (código 225); de "BelasArtes" - Escultura, Filosofia da arte, Gravura e estampagem, História da arte, Pintura, Teoria da arte (código 211) ${ }^{11}$.

Para melhor se compreender esta realidade, apresentamos o enquadramento de "Artesanato", constante na Portaria n. ${ }^{\circ}$ 256/2005, de 16 de Março, já citada atrás: "Os programas de formação em artesanato dizzem respeito às técnicas $e$ às competências associadas a determinados ofícios manuais, tais como joalharia, cerâmica, tecelagem, escultura em madeira, etc. O "Artesanato», neste quadro legal, é entendido em oposição à produção industrial'

Da análise dos programas contidos no "artesanato" verifica-se que incidem sobre várias formações e não encontramos a mais pequena referência a $C R$, o que serve, em nosso entender, para demonstrar a falta de coerência do sistema da CNAEF e, sobretudo, a falta de representatividade da realidade profissional e da realidade formativa em Portugal. Como se fosse razoável considerar o "artesanato" um domínio científico, pois, se o é, porque não existe formação de $1 .^{\circ}, 2 .^{\circ}$ e $3 .^{\circ}$ ciclo com programas de estudos em "artesanato", à semelhança do que acontece, p. e., com a História e com a própria CR?

\subsection{Oferta Formativa de nível superior em Conservação e Restauro no «pós-Bolonha»}

Segundo Karen Borchersen (ENCoRE, Março, 2008 - tradução e adaptação do autor), "ao longo dos últimos cinquenta anos, tornou-se cada vez. mais evidente que a CR coloca problemas muito complexos para serem resolvidos no âmbito dos sistemas existentes da prática, baseados nas habilidades artesanais [entendam-se manuais - dir-se-ia, antes, nas competências do saber-fazer], suportada e controlada por outras disciplinas académicas das ciências humanas e sociais ou das ciências exactas, da terra e da natureza (e.g. a história, história da arte e arqueologia, ou a física, química, geologia, biologia, etc.). Borchersen, acrescenta ainda que, durante esse período, os programas de estudos académicos em CR tornaram-se uma realidade, afirmando-se na Europa, e os seus graduados/diplomados foram entrando no mercado deste sector/domínio, cunhando, com as suas visões de especialistas, o sentido do progresso da actividade de CR e das instituições respectivas, e que, embora diferentes no nível e qualidade da oferta, todos estes programas de estudos tiveram como objectivo reunir as necessárias competências técnicas e práticas relacionadas com as ciências humanas e ciências exactas e da natureza. Eles foram concebidos para oferecer uma linha de ensino/formação estruturada onde a prática era apoiada por um alicerce claro do conhecimento, e onde a pesquisa/investigação podia ser apoiada e incentivada. Durante este tempo, os perigos de pressões e interesses comerciais, que poderiam resultar em intervenções de CR de má qualidade, com resultados potencialmente desastrosos e irreversíveis, também foram reconhecidos ${ }^{12}$.

Em Portugal, felizmente e com algum esforço, tem-se conseguido acompanhar essa linha de evolução, arriscaríamos dizer, não fossem os problemas já identificados, com algum pioneirismo e 
até vanguardismo relativamente a certos países da Europa, senão veja-se a actual oferta disponível no universo das IESP; constante do levantamento da oferta formativa de nível superior em Portugal para o ano lectivo 2010/2011 [tabelas 3, 4 e 5$]^{13}$.

\subsection{Níveis de Qualificação Profissional (NQP)}

O Conselho das Comunidades Europeias definiu 5 Níveis de Qualificação Profissional (NQP), (Decisão no 85/368/CEE de 16 de Julho de 1985) que se mantiveram em vigor, em Portugal, até ao ano de 2009, com a entrada em vigor da Portaria n. ${ }^{\circ} 782 / 2009$, de 23 de Julho, que estabelece, em resultado do "Processo de Bolonha" e da "Reforma do Sistema Educativo em Portugal", ao nível do ensino e formação, o Sistema Nacional de Qualificações (SNQ $)^{14}$, do qual resultam dois instrumentos: o Catálogo Nacional de Qualificações (CNQ), destinado essencialmente a divulgar ofertas de formação contínua; e o Quadro Nacional de Qualificações (QNQ), onde se definem 8 NQP, transpostos do Quadro Europeu de Qualificações Para a Aprendizagem ao Longo da Vida (QEQ), onde são apresentados os indicadores de definição desses 8 níveis, que, por sua vez, especificam os resultados da aprendizagem correspondentes às qualificações de cada nível, em qualquer sistema de qualificações.

No caso da formação académica (em CR), ela correspondia no anterior sistema de qualificação, que só contemplava a formação inicial, aos dois últimos níveis de formação: o Nível IV, correspondente ao grau de bacharel, cujo descritivo era - execução autónoma de um trabalho técnico implicando responsabilidades de concepção e/ou de direcção e/ou de gestão; e o Nível V, correspondente ao grau de licenciado, cujo descritivo era - execução autónoma de uma actividade profissional assalariada ou independente, implicando o domínio dos fundamentos científicos da profissão.

Com a reforma do SNQ e a consequente adopção do QNQ, com os seus $8 \mathrm{NQP}$, verifica-se a existência de um quadro mais abrangente em termos de cobertura dos programas de ensino/formação de nível técnico-profissional e técnico-científico, e, também, mais claro relativamente ao seu enquadramento, definindo resultados da aprendizagem através dos seguintes indicadores: conhecimentos (teóricos e factuais); aptidões (cognitivas e práticas) e competência (responsabilidade e autonomia). Com esta clarificação conseguimos antever um melhor ordenamento das qualificações e, portanto, um quadro mais representativo dos NQP existentes após as várias reformas introduzidas nos sistemas de ensino em Portugal ${ }^{15}$.

Contudo, observando os oito descritores de qualificações, e assumindo neste contexto apenas os quatro mais altos, os descritores de qualificação para formação de nível superior, correspondendo, respectivamente, à formação especializada intermédia que não confere qualquer grau (Cursos de Especialização Tecnológica - CET), Nível 5 (e que permitem e facilitam o acesso ao níveis seguintes); aos graus de bacharel e licenciado, o Nível 6; ao grau de mestre, o Nível 7; e, por fim, ao grau de doutor, o Nível 8; verificamos que subjaz uma omissão, a nosso ver, grave, na medida que não prevê nenhum plano de equivalência entre o anterior sistema de qualificação e o actual, o QNQ, gerando iniquidades entre os profissionais que obtiveram as suas formações nos sistemas "pré-Bolonha" e "pós-Bolonha", de acordo com os graus académicos e tempos de duração inerentes aos dois sistemas "o antigo" e "o actual", conforme se pode observar e concluir através da [tabela 6]. 
Tabela 3. Programas de estudos em Conservação e Restauro em organizações de Ensino Público.

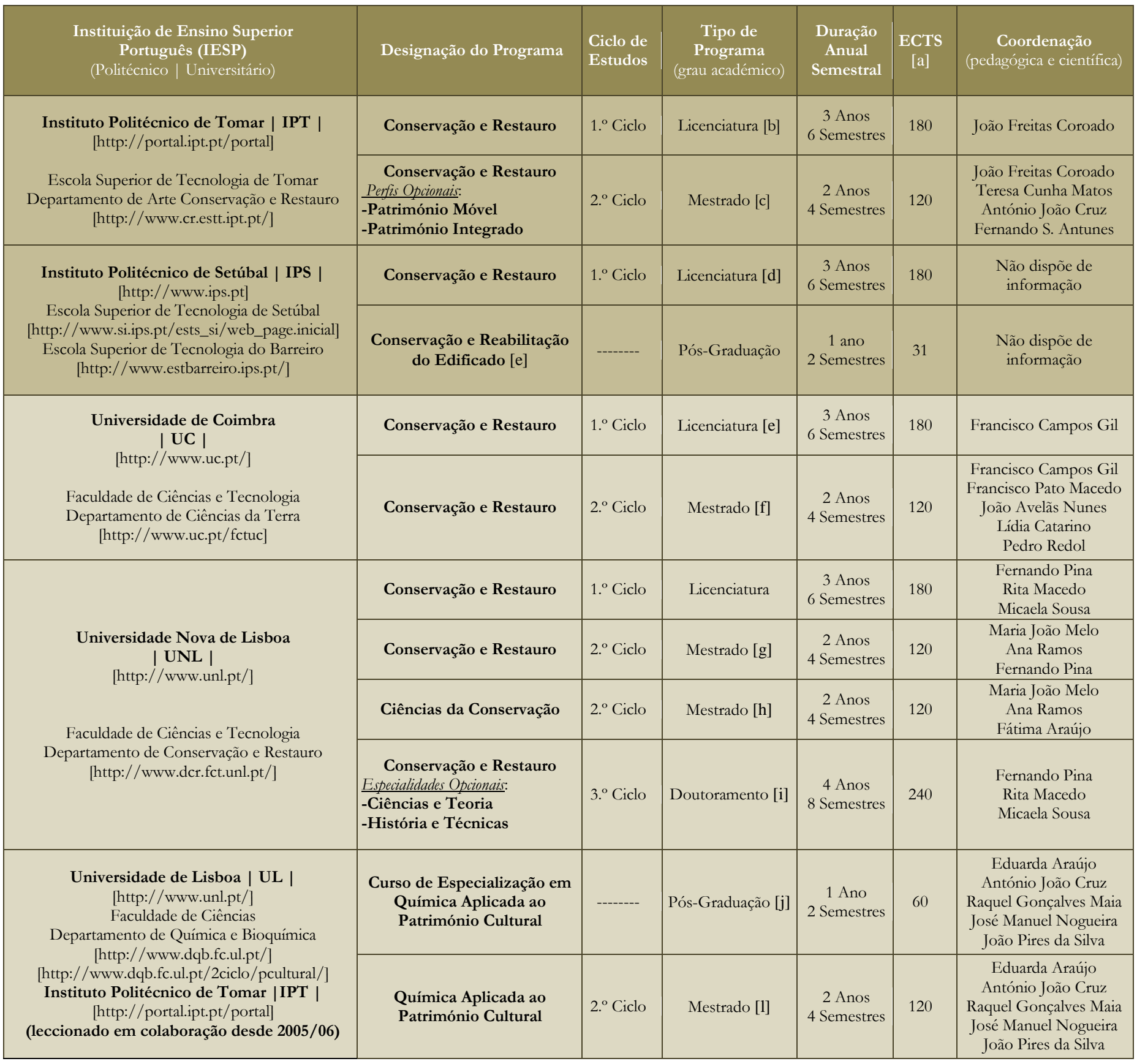

[a] ECTS - European Credit Transfer and Accumulation System (Sistema Europeu de Acumulação e Transferência de Créditos).

[b] No 6. ${ }^{\circ}$ semestre, o aluno desenvolve um Projecto em Conservação e Restauro, em área e especialidade opcionais.

[c] No 2. ${ }^{\circ}$ ano o aluno opta, de acordo com as Normas Regulamentares do Ciclo de Estudos, por desenvolver a unidade curricular de Estágio, em área e especialidade opcionais (via profissional), ou Dissertação (via de investigação aplicada).

[d] O curso obteve parecer positivo e consta na página na Internet do DGES | MCTES onde está listada uma Licenciatura em Conservação e Restauro. No entanto o MCTES, nunca chegou abrir vagas, mesmo para o próximo ano lectivo 2010/2011. $<$ http://www.si.ips.pt/ests_si/NOTICIAS_GERAL.VER_NOTICIA?P_NR=5592>

[e] Na página na Internet do DGES | MCTES está listada uma Licenciatura em Conservação e Restauro, mas tanto quanto nos foi possível apurar nunca chegou a funcionar e nem sequer consta da lista de oferta de cursos da UC |FCT |DCT.

[f] No $1 .^{\circ} \mathrm{e} 2{ }^{\circ}$ semestre, o aluno desenvolve, respectivamente, as unidades curriculares de Projecto $I \mathrm{e} I I$, e no $2 .^{\circ}$ ano, a Dissertação/Estágio e Relatório/Projecto.

[g] No 3..$^{\circ}$ e.$^{\circ}$ semestre, o aluno desenvolve as unidades curriculares de Estágio I e Estágio II associadas à Dissertação. 
[h] No 1. $.^{\circ}, .^{\circ}$ e $4 .^{\circ}$ semestre, o aluno desenvolve unidades curriculares de Projecto de Investigação 1,2 e 3 , associadas à Dissertação.

[i] No $1 .^{\circ}$ ano o aluno frequenta componente curricular do programa doutoral, e nos três anos seguintes desenvolve a Tese.

[j] No 1. ${ }^{\circ}$ ano o aluno frequenta componente curricular do programa do mestrado. Nota: Não abriu candidaturas no ano lectivo 2010/2011.

[1] No 2. ${ }^{\circ}$ ano o aluno desenvolve uma dissertação subordinada a um tema original. Nota: Não abriu candidaturas no ano lectivo 2010/2011.

Tabela 4. Programas de estudos em Conservação e Restauro em organizações de Ensino Privado.

\begin{tabular}{|c|c|c|c|c|c|c|}
\hline $\begin{array}{c}\text { Instituição de Ensino Superior Português } \\
\text { (IESP) } \\
\text { (Politécnico | Universitário) }\end{array}$ & Designação do Programa & $\begin{array}{l}\text { Ciclo de } \\
\text { Estudos }\end{array}$ & $\begin{array}{c}\text { Tipo de } \\
\text { Programa } \\
\text { (grau académico) }\end{array}$ & $\begin{array}{l}\text { Duração } \\
\text { Anual } \\
\text { Semestral }\end{array}$ & $\begin{array}{l}\text { ECTS } \\
{[a]}\end{array}$ & $\begin{array}{c}\text { Coordenação } \\
\text { (pedagógica e científica) }\end{array}$ \\
\hline \multirow{3}{*}{$\begin{array}{c}\text { Fundação Ricardo Espírito Santo Silva } \\
\text { | FRESS | } \\
\text { [www.fress.pt] } \\
\text { Escola Superior de Artes Decorativas } \\
\text { | ESAD | } \\
\text { [http://www.fress.pt/Default.aspx?PageId=6] }\end{array}$} & $\begin{array}{l}\text { Conservação e Restauro } \\
\text { Especialidades Opcionais: } \\
\text {-Pintura e Policromias. } \\
\text {-Revestimentos } \\
\text { Arquitectónicos. } \\
\text {-Artes da Madeira. } \\
\text {-Documentos Gráficos e } \\
\text { Encadernação. }\end{array}$ & 1. ${ }^{\circ}$ Ciclo & Licenciatura & $\begin{array}{c}3 \text { Anos } \\
6 \text { Semestres }\end{array}$ & 180 & $\begin{array}{l}\text { Isabel Mendonça } \\
\text { Nazaré Tojal }\end{array}$ \\
\hline & \begin{tabular}{l}
\multicolumn{1}{|c|}{ Conservação e Restauro } \\
Especialidades Opcionais: \\
-Revestimentos \\
Arquitectónicos. \\
-Artes da Madeira. \\
-Documentos Gráficos e \\
Encadernação.
\end{tabular} & 2. Ciclo & Mestrado [b] & $\begin{array}{c}2 \text { Anos } \\
4 \text { Semestres }\end{array}$ & 120 & $\begin{array}{l}\text { Isabel Mendonça } \\
\text { Nazaré Tojal }\end{array}$ \\
\hline & $\begin{array}{l}\text { Conservação e Reabilitação } \\
\text { de Interiores }\end{array}$ & 2. Ciclo & Mestrado [c] & $\begin{array}{c}2 \text { Anos } \\
4 \text { Semestres }\end{array}$ & 120 & Hélder Carita \\
\hline $\begin{array}{c}\text { Escola Superior de Tecnologias e Artes de } \\
\text { Lisboa | ESTAL | } \\
\text { [http://estal.pt/site/] }\end{array}$ & $\begin{array}{l}\text { Conservação e Restauro } \\
\text { Vertentes Opcionais: } \\
\text {-CR em Museus } \\
\text {-CR em Património } \\
\text { Edificado }\end{array}$ & 1. ${ }^{\circ}$ Ciclo & Licenciatura [d] & $\begin{array}{c}3 \text { Anos } \\
6 \text { Semestres }\end{array}$ & 180 & $\begin{array}{l}\text { Não dispõe de } \\
\text { informação }\end{array}$ \\
\hline \multirow{2}{*}{$\begin{array}{l}\text { Universidade Lusófona de Humanidades e } \\
\text { Tecnologias } \\
\text { | ULH | } \\
\text { [http://www.ulusofona.pt/] } \\
\text { Escola de Belas Artes } \\
\text { belas-artes] } \\
\text { [http://www.ulusofona.pt/index.php/escola-de- } \\
\text { Faculdade de Arquitectura Urbanismo Geografia } \\
\text { e Arte } \\
\text { [http://www.ulusofona.pt/index.php/faculdade- } \\
\text { de-arquitectura-urbanismo-geografia-e-artes] }\end{array}$} & Conservação e Restauro & 1. ${ }^{\circ}$ Ciclo & Licenciatura & $\begin{array}{c}3 \text { Anos } \\
6 \text { Semestres }\end{array}$ & 180 & $\begin{array}{l}\text { Augusto P. Brandão } \\
\text { M. a Alexandra Campos }\end{array}$ \\
\hline & $\begin{array}{c}\text { Conservação e Restauro do } \\
\text { Património Cultural }\end{array}$ & 2. Ciclo & Mestrado [e] & $\begin{array}{c}2 \text { Anos } \\
4 \text { Semestres }\end{array}$ & 120 & $\begin{array}{l}\text { Augusto P. Brandão } \\
\text { M. A Alexandra Campos }\end{array}$ \\
\hline \multirow{2}{*}{$\begin{array}{l}\text { Universidade Portucalense Infante } \\
\text { D. Henrique | UPT | } \\
\text { [http://www.uportu.pt/site-scripts/] }\end{array}$} & Conservação e Restauro & 1. ${ }^{\circ}$ Ciclo & Licenciatura & $\begin{array}{l}3 \text { Anos } \\
6 \text { Semestres }\end{array}$ & 180 & Fátima Matos Silva \\
\hline & $\begin{array}{l}\text { Património Artístico, } \\
\text { Conservação e Restauro }\end{array}$ & 2. Ciclo & Mestrado [q] & $\begin{array}{l}2 \text { Anos } \\
\text { 4 Semestres }\end{array}$ & 120 & $\begin{array}{l}\text { Luísa Reis Lima } \\
\text { Luís Mariz }\end{array}$ \\
\hline
\end{tabular}

[a] ECTS - European Credit Transfer and Accumulation System (Sistema Europeu de Acumulação e Transferência de Créditos).

[b] No $3 .^{\circ}$ e $4 .^{\circ}$ semestre, o aluno desenvolve a unidade curricular de Estágio com Relatório.

[c] № 2. ${ }^{\circ}$ ano, o aluno desenvolve as unidades curriculares de Seminários Oficinais de Conservação e Restauro e Seminário de Acompanhamento Científico, no 3. ${ }^{\circ}$ semestre, e, opcionalmente, Dissertação / Projecto / Estágio, nos dois semestres.

[d] No $3 .^{\circ}$ e $4 .^{\circ}$ semestre, o aluno desenvolve, respectivamente, as unidades curriculares de Workshop e de Projecto de Intervenção.

[e] No 3..$^{\circ}$ 4. ${ }^{\circ}$ semestre, o aluno desenvolve a unidade curricular de Dissertação (Científica ou Profissional) e projecto de âmbito profissional (estágio). 
[f] No 3..$^{\circ}$ e $4^{\circ}$ semestre, o aluno desenvolve a unidade curricular de Dissertação, uma investigação original, em área à escolha integrada no âmbito geral do mestrado,

[g] No 2. ${ }^{\circ}$ ano, o aluno desenvolve, a unidade curricular de Dissertação.

Tabela 5. Programas de estudos em Conservação e Restauro em organizações de Ensino Concordatário.

\begin{tabular}{|c|c|c|c|c|c|c|}
\hline $\begin{array}{c}\text { Instituição de Ensino Superior Português } \\
\text { (IESP) } \\
\text { (Politécnico | Universitário) }\end{array}$ & Designação do Programa & $\begin{array}{l}\text { Ciclo de } \\
\text { Estudos }\end{array}$ & $\begin{array}{l}\text { Tipo de } \\
\text { Programa } \\
\quad \text { (grau } \\
\text { académico) }\end{array}$ & $\begin{array}{l}\text { Duração } \\
\text { Anual } \\
\text { Semestral }\end{array}$ & $\begin{array}{l}\text { ECTS } \\
{[\mathrm{a}]}\end{array}$ & $\begin{array}{l}\text { Coordenação } \\
\text { (pedagógica e } \\
\text { científica) }\end{array}$ \\
\hline \multirow{3}{*}{$\begin{array}{c}\text { Universidade Católica Portuguesa } \\
\text { | UCP | } \\
\text { [http://www.ucp.pt/] } \\
\text { Escola das Artes } \\
\text { (Porto - Pólo da Foz) } \\
\text { Departamento de Arte e Restauro } \\
\text { [http://www.porto.ucp.pt] } \\
\text { [http://www.artes.ucp.pt/] }\end{array}$} & $\begin{array}{c}\text { Arte - Conservação e } \\
\text { Restauro }\end{array}$ & 1. ${ }^{\circ}$ Ciclo & Licenciatura & $\begin{array}{c}3 \text { Anos } \\
6 \text { Semestres }\end{array}$ & 180 & $\begin{array}{c}\text { Gonçalo Vasconcelos e } \\
\text { Sousa } \\
\text { Ana Calvo } \\
\end{array}$ \\
\hline & $\begin{array}{l}\text { Conservação de Bens } \\
\text { Culturais } \\
\text { Especialidades Opcionais: } \\
\text { Pintura } \\
\text { Escultura }\end{array}$ & 2. ${ }^{\circ}$ Ciclo & Mestrado [b] & $\begin{array}{c}2 \text { Anos } \\
4 \text { Semestres }\end{array}$ & 120 & $\begin{array}{c}\text { Gonçalo Vasconcelos e } \\
\text { Sousa } \\
\text { Ana Calvo }\end{array}$ \\
\hline & $\begin{array}{l}\text { Conservação de Bens } \\
\text { Culturais } \\
\frac{\text { Especialidades Opcionais: }}{\text { Pintura }} \\
\text { Materiais Inorgânicos }\end{array}$ & 3. ${ }^{\circ}$ Ciclo & $\begin{array}{l}\text { Doutoramento } \\
{[\mathrm{c}]}\end{array}$ & $\begin{array}{c}3 \text { Anos } \\
6 \text { Semestres }\end{array}$ & 180 & $\begin{array}{c}\text { Gonçalo Vasconcelos e } \\
\text { Sousa } \\
\text { Ana Calvo }\end{array}$ \\
\hline
\end{tabular}

[a] ECTS - European Credit Transfer and Accumulation System (Sistema Europeu de Acumulação e Transferência de Créditos).

[b] No $3 .^{\circ}$ semestre, o aluno desenvolve, as unidades curriculares de Colóquios de Investigação e Projecto de Dissertação, e no $4 .^{\circ}$ semestre, a Dissertação.

[c] No $1 .^{\circ}$ e $2 .^{\circ}$ semestre, o aluno frequenta componente curricular do programa doutoral, no $3 .^{\circ}$ frequenta as unidades de Metodologia Avançada de Investigação e Colóquios de Investigação, e nos três semestres seguintes desenvolve a Tese.

Tabela 6. Análise comparativa da atribuição de Níveis de Qualificação Profissional.

\begin{tabular}{|c|c|c|c|c|c|c|}
\hline \multicolumn{3}{|c|}{$\begin{array}{l}\text { Sistema de Ensino-Formação de Nível Superior } \\
\text { "pré-Bolonha" }\end{array}$} & \multicolumn{3}{|c|}{$\begin{array}{l}\text { Sistema de Ensino-Formação de Nível Superior } \\
\text { "pós-Bolonha" }\end{array}$} & \multirow{2}{*}{$\begin{array}{l}\text { Diferencial } \\
\text { de tempo entre } \\
\text { formações do } \\
\text { mesmo grau } \\
\text { nos } 2 \text { sistemas }\end{array}$} \\
\hline $\begin{array}{l}\text { Grau } \\
\text { Académico }\end{array}$ & $\begin{array}{l}\text { Ciclo de Estudos } \\
\text { | Duração }\end{array}$ & $\begin{array}{c}\text { Nível } \\
\text { Qualificação } \\
\text { Profissional } \\
\text { (NQP) }\end{array}$ & $\begin{array}{l}\text { Grau } \\
\text { Académico }\end{array}$ & $\begin{array}{l}\text { Ciclo de Estudos } \\
\text { | Duração }\end{array}$ & $\begin{array}{c}\text { Nível } \\
\text { Qualificação } \\
\text { Profissional } \\
\text { (NQP)|(QNQ) }\end{array}$ & \\
\hline Bacharelato & 1. ${ }^{\circ}$ ciclo | 3 anos & IV & CET [a] & $1,5-2$ anos & 5 & $1-1,5$ anos \\
\hline $\begin{array}{l}\text { Licenciatura } \\
{[\text { b] }}\end{array}$ & $\begin{array}{c}\left(1 .^{\circ}\right)+2 .^{\circ} \text { ciclo | } \\
4-6 \text { anos; }(3)+2 \text { anos }\end{array}$ & $\mathbf{V}$ & Licenciatura & 1. ${ }^{\circ}$ ciclo | 3 anos & 6 & 2 anos \\
\hline Mestrado & 2-4 anos & ---------- & Mestrado [c] & $\begin{array}{c}\left(1 .^{\circ}\right)+2 .^{\circ} \text { ciclo | } \\
4-5 \text { anos; }(3)+2 \text { anos }\end{array}$ & 7 & 0-2 anos \\
\hline Doutorado & 4-6 anos & --------- & Doutorado & $3 .^{\circ}$ ciclo | 3 anos & 8 & 1-3 anos \\
\hline \multicolumn{3}{|c|}{$\begin{array}{c}\text { Duração média para obtenção do grau de doutor: } \\
=12 \text { Anos de Ensino/Formação }\end{array}$} & \multicolumn{3}{|c|}{$\frac{\text { Duração média para obtenção do grau de doutor: }}{=8 \text { Anos de Ensino/Formação }}$} & \\
\hline
\end{tabular}

[a] Curso de Especialização Tecnológica - Não confere grau académico.

[b] Podia ser uma licenciatura mono ou bietápica.

[c] Pode ser mestrado integrado ou não. 
Parece-nos que o principal, mais importante e, aparentemente, único aspecto negativo que identificamos no QNQ, é o facto de ter implícita uma desvalorização dos profissionais e das formações de nível superior da fase "pré-Bolonha", que conferiram os graus de bacharelato, licenciatura (mono e bietápica) e mestrado. Efectivamente, o QNQ nivela por defeito, na transposição entre os dois sistemas de qualificação, os antigos graus face aos actuais, que mantém as mesmas designações, mas, em média, tem quase metade do tempo de formação. Sabendo, os agentes do ensino/formação e os pedagogos em geral, que um ano de trabalho faz muita diferença no processo formativo de qualquer individuo e na sedimentação dos seus saberes e competências.

A título de exemplo ilustramos o seguinte caso que decorre da aplicação do novo QNQ e que, recorde-se, é transposto do QEQ:

- Um conservador-restaurador licenciado "pré-Bolonha", com cinco anos de formação (que incluía um estágio anual no 5 . $^{\circ}$ ano) e que tinha o NQP-V, actualmente, com a aplicação do novo QNQ, o mesmo profissional vê-se com o NQP-6, mas nivelado com o licenciado "pós-Bolonha" que tem apenas três anos de formação, ou seja, menos dois anos (e sem frequência de estágio anual, realizando apenas um projecto em CR com a duração de um semestre lectivo, e onde, na maioria dos casos, desenvolve apenas a componente do saber-saber).

Como se poderá perceber este exemplo estende-se a outros níveis e graus do SNQ, o que lança muitas interrogações por parte dos profissionais do sector CR (e de outros), sobretudo quando se colocam questões relacionadas com concursos e carreiras profissionais, campos onde parecem começar a ocorrer injustiças e diferenciações negativas que não abonam ao equilíbrio e tranquilidade no sector.

\section{Conclusão:}

Deste nosso contributo, parece ressaltar a seguinte conclusão é que, em primeiro lugar, apesar de ter um longo caminho já percorrido e estando próximo de atingir a maturidade, o sector e os profissionais da $\mathrm{CR}$, ainda têm muito terreno para desbravar e conquistar no sentido do reconhecimento socioprofissional. Parece-nos que esse reconhecimento, para além de se conseguir no dia-a-dia, com o esforço directo dos profissionais, pode começar por obter-se através da resolução destes vários "sistemas" de enquadramento, classificação e de valoração.

Mas essa mudança só a vemos concretizável num futuro mais próximo com um mecanismo institucional de influência positiva que se possa gerar a partir da criação de uma Ordem Profissional dos Conservadores Restauradores que represente efectiva e obrigatoriamente todos os profissionais da CR (com formação inicial de nível superior - com duração de 5 anos), e que, pelo seu enquadramento legal (semelhante às restantes ordens profissionais existentes), possa ter expressão e peso institucionais verdadeiramente mobilizadores de indivíduos e de causas que representem uma classe profissional e não apenas um grupo ou associação, que, por muito meritórios e necessários sejam os seus contributos, não podem assumir o peso representativo de uma ordem profissional.

Em segundo lugar, é preciso fazer um esforço no sentido de promover a evolução de uma oferta formativa ajustada às necessidades de competências técnicas e científicas dos profissionais deste sector e, para isso, é indispensável conhecer a realidade, identificar as tendências, e, por fim, delinear prospectivamente o futuro, através de uma estratégia adequada e que seja validada entre os vários parceiros.

É neste sentido que se nos oferece dizer que o sector/domínio da actividade de CR é:

- Uma realidade construída a partir da segunda metade do século XX, mas a um ritmo muito mais rápido no último quartel do mesmo século; e extremamente intenso, no virar da primeira 
década do século XXI, de tal modo, que alguém informado já não poderá levantar dúvidas que constitui um efectivo, inquestionável e particular sector de actividade, com múltiplos desdobramentos em áreas funcionais (transversais) e especialidades organizadas por categorias de materiais e de técnicas de produção dos bens culturais.

É uma ficção, na medida em que se olha de fora para esta actividade com perspectivas e enquadramentos assentes em modelos ultrapassados, ou, se actualizados, delineados por autores externos à actividade, logo, nem sempre "a sentem" ou interpretam da melhor maneira; e, na medida que a observação interna, por parte dos seus profissionais, também, muitas das vezes, se pauta por alguns vícios de forma no modo como se estrutura, por ser errática, tímida e não conquistar o espaço que é seu de direito próprio.

Espera-se que passe de uma utopia, dos seus profissionais e defensores, se todos os intervenientes acreditarem nas suas capacidades, se mobilizarem para conquistarem a suas competências e saírem à procura do espaço que lhes pertence nesse "concerto" entre as diferentes actividades e profissionais dos vários sectores e domínios de actividade.

\section{Notas}

[1] "Processo de Bolonha" [FicheiroPDF:<plano_accao_mces $>$ ]

$<$ http://www.ccisp.pt/documentos/bolonha/outros/processo_bolonha.pdf $>$ [Consulta: $17 / 7 / 2010]$.

[2] "The Bologna Declaration of 19 June 1999: Joint declaration of the European Ministers of Education" [Ficheiro PDF: $<$ bologna_declaration>]<http://www.ccisp.pt/documentos/bolonha/outros/bologna_declaration. pdf $>$ [Consulta: 17/7/2010].

[3] Decreto-Lei N. ${ }^{\circ}$ 74/2006, de 24 de Março, sobre “Graus Académicos e Diplomas do Ensino Superior" do Ministério da Ciência, Tecnologia e Ensino Superior [Portugal] [Ficheiro PDF: “22422257” (DL_74_2006)].<http://dre.pt/pdf1sdip/2006/03/060A00/22422257.pdf> [Consulta: $17 / 7 / 2010]$.

[4] “Classificação Portuguesa das Actividades Económicas (CAE-Rev.3)”, Lisboa, INE, 2007, pp. 3738 .

<http://metaweb.ine.pt/sine/.\%5Canexos\%5Cpdf\%5CApresentacaoCAERev3.pdf $>$ [Consulta: 20/7/2010].

[5] Portaria no 1193/2003, de 13 de Outubro de 2003, DR 237 - Série I-B, que "Regula o processo de reconhecimento dos artesãos e das unidades produtivas artesanais e ainda a organização e funcionamento do Registo Nacional do Artesanato, Emitida pelos Ministérios das Finanças, da Economia, da Agricultura, Desenvolvimento Rural e Pescas, da Educação, da Cultura e da Segurança Social e do Trabalho. <http://www.iapmei.pt/iapmei-leg-03.php?lei=2178> [Consulta: 25/7/2010].

[6] Nos termos previstos no Decreto-Lei n. ${ }^{\circ}$ 41/2001, de 9 de Fevereiro, com a redacção que lhe foi dada pelo Decreto-Lei n. ${ }^{\circ} 110 / 2002$, de 16 de Abril.

[7] Decreto-Lei 140/2009, de 15 de Junho, DR 113 - Série I, que estabelece o "Regime Jurídico dos estudos, projectos, relatórios, obras ou intervenções sobre bens culturais classificados, ou em vias de classificação, de interesse nacional, de interesse público ou de interesse municipal" $<$ http://www.portaldacultura.gov.pt/ministeriocultura/Pages/legislacao_cultural.aspx $>$ [Consulta: 29/7/2010]. 
[8] "Revised Field Of Science And Technology (Fos) Classification In The Frascati Manual". Directorate For Science, Technology And Industry Committee For Scientific And Technological Policy, Working Party of National Experts on Science and Technology Indicators. Organisation for Economic Co-operation and Development (OCDE), 26-Feb-2007.

<http://www.oecd.org/dataoecd/36/44/38235147.pdf> [Consulta: 25/7/2010].

[9] “Classificação de Domínios Científicos e Tecnológicos, 2007 (FOS)”, Gabinete de Planeamento, Estratégia, Avaliação e Relações Internacionais | MCTES. (ficheiro PDF). Disponível em: $<$ http://www.gpeari.mctes.pt/?idc=13\&idi=213523> [Consulta: 25/07/2010].

[10] Portaria n. ${ }^{\circ}$ 256/2005, de 16 de Março. DR 53 - Série I-B, que "Regula a Aplicação da Classificação Nacional de Áreas de Educação e Formação”. Emitida pelo Ministério das Actividades Económicas e Trabalho.<http://www.dgert.mtss.gov.pt/Emprego\%20e\%20Formacao\%20Profissional/doc_empr ego/Portaria256_2005_CNAEF.pdf> [Consulta: 26/7/2010].

[11] "Aplicação da Classificação Nacional de Áreas de Educação e Formação (CNAEF) - Pesquisa de cursos de Ensino Superior de acordo com a CNAEF”. Gabinete de Planeamento, Estratégia, Avaliação e Relações Internacionais | MCTES <http://www.gpeari.mctes.pt/?idc=60\&form=1> [Consulta: 25/07/2010].

[12] “A Disciplina de Conservação e Restauro". European Network for Conservation-Restoration Education (ENCoRE). Edited by: Karen Borchersen, 28 the March 2008. <http://www.encoreedu.org/encore/DesktopDefault.aspx> [Consulta: 26/7/2010].

[13] "Oferta Formativa: Cursos do Ensino Superior que conferem Grau académico - Licenciaturas, Mestrados e Doutoramentos”. Direcção-Geral do Ensino Superior, do Ministério da Ciência Tecnologia e do Ensino Superior.

<http://www.dges.mctes.pt/DGES/pt/OfertaFormativa/CursosConferentesDeGrau/> [Consultado: 18/07/2010].

[14] “Sistema Nacional de Qualificações (SNQ)". In: Ponto Nacional Para a Referência das Qualificações (PNQ).

<http://portal.iefp.pt/portal/page?_pageid=177,217836\&_dad=gov_portal_iefp\&_schema=GOV _PORTAL_IEFP> [Consultado: 26/07/2010].

[15] “O Quadro Europeu de Qualificações Para a Aprendizagem ao Longo da Vida”. Direcção-Geral para a Educação e Cultura da Comissão Europeia

<http://ec.europa.eu/education/pub/pdf/general/eqf/leaflet_pt.pdf> [Consultado: 26/07/2010].

\section{Bibliografía}

ANTUNES, João F. (2003). "Conservação e Restauro; Que formação para que perfis profissionais?” (Intervenção no Debate). Nos 2. ${ }^{\circ}$ E Encontros Científicos do IPCR: Lisboa: Instituto Português da Conservação e Restauro, 76-77.

INSTITUTO PARA A QUALIDADE NA FORMAÇÃO - IQF [Coordenação de Sandra Lameira] (2006). Evolução das Qualificações e Diagnóstico das Necessidades de Formação: Preservação Conservação e Valorização do Património Cultural. Em Portugal: Estudo que integra uma Separata com os Perfis Profissionais. Colecção de Estudos Sectoriais N. ${ }^{\circ}$ 31. Lisboa: IQF.

ORGANIZAÇÃO DAS NAÇÕES UNIDAS PARA A EDUCAÇÃO, CIÊNCIA E CULTURA (UNESCO) (2006) - Classificação Internacional Tipo da Educação (CITE) 1997. (Reedição da Versão em Português). UNESCO. 
ENCoRE - European Network for Conservation-Restoration Education. [René Larsen (ed. Lit)] (2008). "ENEWSLETTER 1" < http://www.encore-edu.org/encore/desktopdefault.aspx?tabindex=1\&tabid=286> [Consultado: 24/07/2010].

\section{Sítios na Internet}

ASSOCIAÇ̃̃O PROFISSIONAL DE CONSERVADORES-RESTAURADORES DE PORTUGAL. $<$ http://www.arp.org.pt/>

EUROPEAN CONFEDERATION OF CONSERVATOR-RESTORERS' ORGANISATIONS.

$<$ http://www.ecco-eu.org/>

\section{EUROPEAN NETWORK FOR CONSERVATION-RESTORATION EDUCATION}

$<$ http:/ / www.encore-edu.org/encore/DesktopDefault.aspx?tabindex =1\&tabid=1>

GRÉMIO DAS EMPRESAS DE CONSERVAÇÃO E RESTAURO DO PATRIMÓNIO

ARQUITECTÓNIVO < http://www.gecorpa.pt/>

INSTITUTO DE EMPREGO E FORMAÇÃO PROFISSIONAL

$<$ http://portal.iefp.pt/>

PORTAL DA CONSERVASÇÃO E RESATURO

$<$ http://www.prorestauro.com/>

PORTAL DA CULTURA - MINISTÉRIO DA CULTURA DE PORTUGAL

$<$ http://www.portaldacultura.gov.pt $>$

\section{Siglas e Acrónimos}

CAE - Sistema de Classificação das Actividades Económicas

CAE-Rev.1-3 - Classificação das Actividades Económicas - Revisão 1 a 3

CDCT - Sistema de Classificação de Domínios Científicos e Tecnológicos (Vide: FOS)

CE - Comunidade Económica | Comissão Europeia

CEE - Comunidade Económica Europeia

CITA - Classificação Internacional Tipo de Todos os Ramos da Actividade Económica (em francês CITI e em Inglês ISIC)

CITE - Classificação Internacional Tipo da Educação

CNAEF - Classificação Nacional de Áreas de Educação e Formação

CNBS - Classificação Nacional de Bens e Serviços

CNE - Conselho Nacional de Estatística

CNQ - Catálogo Nacional de Qualificações

CR - Conservação e Restauro

CSE - Conselho Superior de Estatística

DGES - Direcção-Geral do Ensino Superior (MCTES)

EEES - Espaço Europeu de Ensino Superior

EHEA - European Higher Education Area

ENCoRE - European Network for Conservation-Restoration Education

EUROSTAT - European Statistics (Serviços de Estatística da Comunidade Europeia) 
FOS - Fields of Science and Technology (Classificação de Domínios Científicos e Tecnológicos)

GE-IIC - Grupo Español - International Institute for Conservation of Historic and Artistic Works

GPEARI - Gabinete de Planeamento, Estratégia, Avaliação e Relações Internacionais (MCTES)

GRP - Governo da República Portuguesa

IEFP - Instituto de emprego e Formação Profissional

IES - Instituições de Ensino Superior

IESP - Instituições de Ensino Superior Português

IIC - International Institute for Conservation of Historic and Artistic Works

IMC - Instituto dos Museus e da Conservação (Antigo Instituto Português da Conservação e Restauro IPCR)

INE - Instituto Nacional de Estatística

IQF - Instituto para a Qualidade na Formação

MCTES - Ministério da Ciência, Tecnologia e Ensino Superior

MTSS - Ministério do Trabalho e da Solidariedade Social

NACE - Nomenclatura Geral das Actividades Económicas das Comunidades Europeias

NESTI - National Experts on Science and Technology Indicators

NQP - Níveis de Qualificação Profissional

OCDE (OECD) - Organização para a Cooperação e Desenvolvimento Económico

ONU (UN) - Organização das Nações Unidas

PPART - Programa de Promoção dos Ofícios e das Microempresas Artesanais

PCVPC - Preservação, Conservação e Valorização do Património Cultural em Portugal

QEQ - Quadro Europeu de Qualificações para a Aprendizagem ao Longo da Vida

QNQ - Quadro Nacional de Qualificações

SEN - Sistema Estatístico Nacional

SNQ - Sistema Nacional de Qualificações (Português)

SQP - Sistema de Qualificação Profissional

SESP - Sistema de Ensino Superior Português

UNESCO - Organização das Nações Unidas para a Educação, a Ciência e a Cultura.

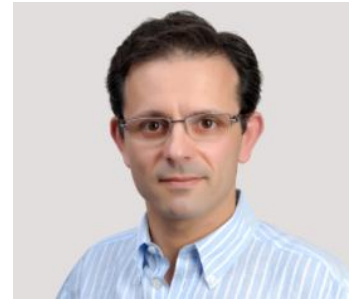

Portal na Internet do IPT: http://portal.ipt.pt/portal . Sítio na Internet DACR: http://www.cr.estt.ipt.pt/ E-

mail: fantunes@ipt.pt

\section{F. dos Santos Antunes}

Instituto Politécnico de Tomar - IPT | Escola Superior de Tecnologia de Tomar ESTT

Departamento de Arte, Conservação e Restauro - DACR | Laboratório de Conservação e Restauro de Madeiras

Av. Dr. Aurélio Ribeiro | Campus da Quinta do Contador. 2300-313 TOMAR | PORTUGAL. Telefones: (++351) 249328100 / 249328130 | Telefax: (++351) 249328135 
Fernando dos Santos Antunes é Conservador Restaurador, docente da Área Científico-Pedagógica de Conservação Restauro (1994-?) e responsável pelo Laboratório de Conservação e Restauro de Madeiras do DACR (1996-?).

Actualmente frequenta o Programa de Doutoramento em Conservação de Bens Culturais, área de especialização em Pintura, da Escola das Artes da Universidade Católica Portuguesa - Porto (2009-?).

É Mestre em História da Arte, na área de especialização em Teorias de Conservação e Restauro do Património Artístico (2003, pela Universidade Lusíada de Lisboa, onde frequentou a pós-graduação em História da Arte (2001).

É Licenciado em Arte Arqueologia e Restauro, na vertente de Arte Lusíada (1997), e Bacharel em Tecnologia em Conservação e Restauro (1993), pela Escola Superior de Tecnologia de Tomar, do Instituto Politécnico de Tomar.

Tem leccionado (1994-?) nos programas formativos dos vários ciclos de estudos de Bacharelato, Licenciatura e Mestrado em Conservação e Restauro, do IPT, em unidades curriculares das áreas de gestão da conservação, de preservação (de colecções), e de conservação e restauro, nas especialidades de mobiliário, estruturas e artefactos em madeiras, retabulística, e da área de técnicas de produção artística aplicada (nas especialidades mencionadas). Como docente, tem ainda, assegurado orientações técnicas e científicas de projectos e estágios em conservação e restauro, e serviço organizacional destacando-se as funções de membro da Comissão de Coordenação do Curso de Mestrado em Conservação e Restauro e de Coordenador da Comissão de Estágios do DACR. 